\title{
Sedative and analgesic validity and administration routes of dexmedetomidine and fentanyl combined with ketamine in awake fiberoptic intubation: An exploratory randomized controlled trial
}

\section{Chunzhu Li}

Shanghai Jiao Tong University School of Medicine

Jiali Peng

Shanghai Jiao Tong University School of Medicine

\section{Yu Sun}

Shanghai Jiao Tong University School of Medicine

\section{Rong $\mathrm{Hu}$}

Tongren Hospital Shanghai Jiaotong University School of Medicine

Hao Wang

Shanghai Jiao Tong University School of Medicine

Jia Yan (D mzkyanj@163.com)

Shanghai Jiao Tong University School of Medicine https://orcid.org/0000-0003-4507-7469

\section{Hong Jiang}

Shanghai Jiao Tong University School of Medicine

Research article

Keywords: ketamine, dexmedetomidine, fentanyl, awake intubation, sedation, analgesia

Posted Date: April 10th, 2020

DOl: https://doi.org/10.21203/rs.3.rs-16108/v2

License: (c) (i) This work is licensed under a Creative Commons Attribution 4.0 International License.

Read Full License 


\section{Abstract}

Background: Awake fiberoptic bronchoscope intubation (AFOBI) is the gold standard technique for the management of patients with difficult airways. Adequate sedation and analgesia are essential for successful AFOBI. The aim of this study was to evaluate the sedative and analgesic validity and administration routes of dexmedetomidine and fentanyl combined with ketamine in awake fiberoptic intubation.

Methods: Patients undergoing head and neck surgery under general anesthesia with predicted difficult airways were included. Participants were randomly assigned to 6 different groups $(n=6)$ : groups 1-3 were intravenous (IV), while groups 4-6 were intranasal (IN) (group 1: dexmedetomidine (DEX) $1 \mu \mathrm{g} / \mathrm{kg}+$ fentanyl (FEN) $1 \mu \mathrm{g} / \mathrm{kg}$; groups 2-3: DEX $1 \mu \mathrm{g} / \mathrm{kg}$ + FEN $0.7 \mu \mathrm{g} / \mathrm{kg}$ + ketamine (KTM) 0.1/0.2 mg/kg; group 4: DEX $1.5 \mu \mathrm{g} / \mathrm{kg}+$ FEN $1.4 \mu \mathrm{g} / \mathrm{kg}$; and groups 5-6: DEX $1 \mu \mathrm{g} / \mathrm{kg}+\mathrm{FEN} 1 \mu \mathrm{g} / \mathrm{kg}+\mathrm{KTM} 0.4 / 0.6$ $\mathrm{mg} / \mathrm{kg}$ ). The visual analog scale (VAS) score during intubation, time required for the modified observer's assessment of alertness/sedation scale (OAA/S) score to reach above 2 and for the bispectral index (BIS) to decrease to $60-80$, motor activity assessment scale (MAAS) score, changes in vital signs and adverse effects were recorded.

Results: Among the IV groups, the VAS score of group $1(5.65 \pm 2.11)$ was higher than those of group 2 $(1.89 \pm 2.16, P=0.012)$ and group $3(1.15 \pm 0.98, P=0.001)$. Among the IN groups, the VAS score was lower in group $6(0.86 \pm 1.27)$ than in group $4(7.20 \pm 2.70, P<0.001)$ and group $5(3.93 \pm 2.73, P=$ 0.031). Participants in group 5 and group 6 were less likely to cough when intubated than those in group $4(P=0.002)$, while the differences among IV groups were not significant. There were no significant differences in the other endpoints.

Conclusions: Our study indicates that the addition of subanesthetic doses of ketamine, either intravenous or intranasal, could reduce the fentanyl and dexmedetomidine consumption used in AFOBI and provide better sedative and analgesic effects.

Trial registration: Chinese Clinical Trial Registry (www.chictr.org.cn; ChiCTR1900021185), prospectively registered on February 1st, 2019.

\section{Background}

The estimated incidence of difficult airways during clinical anesthesia is $1-18 \%$ [1, 2]. Severe events may occur, such as respiratory depression, hypoventilation, hypoxemia, brain damage and even death if the patient's airway is not secured [3]. Although local anesthesia and many types of medicines are used to mitigate anxiety and pain, awake intubation can be an extremely unpleasant experience. Inadequate sedative and analgesic effects of a low-dose single-agent often result in inability to cooperate with the tracheal intubation procedure for patients. However, excessive sedation and analgesia can lead to severe adverse effects, such as hypoventilation and inhibition of the circulatory systems, which may threaten the lives and safety of patients $[4,5]$. 
Dexmedetomidine (DEX) is a selective a-2-adrenoceptor agonist that has the ability to sedate, functions as an anxiolysis, is analgesic sparing, and reduces salivary secretion [6]. It can induce a 'awakable' state that mimics the physiological sleep state. There have been many studies on the use of dexmedetomidine in awake fiberoptic bronchoscopy intubation (AFOBI) [7]. A recent review reported that dexmedetomidine can cause fewer desaturation episodes than propofol and opioids when used in AFOBI [8]. As a classic opioid analgesic, fentanyl (FEN) can pass through the blood-brain barrier and takes effect quickly due to its high lipid solubility. When used in excessive doses, fentanyl can cause respiratory depression, asphyxia, muscle stiffness and bradycardia. However, it cannot provide adequate analgesia at low doses. Fentanyl is thus often used in combination with other anesthetics in clinical scenarios to achieve sufficient analgesia and to avoid potential adverse events.

Ketamine (KTM) is a N-methyl-D-aspartate (NMDA) receptor antagonist and is used for sedation and analgesia in children as well as adults. It can provide an adequate analgesic effect at subanesthetic doses ( $<1 \mathrm{mg} / \mathrm{kg}$ ) while having a rather fast onset [9]. Despite its mild respiratory depressive effects, ketamine has potent sympathetic effects that can increase heart rate, blood pressure and bronchiectasis. It is suitable for patients with circulatory instability or asthma $[10,11]$. However, the adverse reactions caused by excessive doses of ketamine, including increased sputum production, brain metabolism and cerebral blood flow, can be alleviated by combining it with other complementary intravenous anesthetics [12]. Low-dose ketamine can reduce the target concentration of dexmedetomidine required for the loss of consciousness, enhance the sedative effect of the dexmedetomidine, and ensure more stable hemodynamics [13]. Furthermore, low-dose ketamine can significantly reduce the dosage of fentanyl required for reaching a satisfactory sedative effect when used in combination with dexmedetomidine [14].

In addition to intravenous application, intranasal application is another common route of drug administration. The bioavailability of intranasal dexmedetomidine can reach $82 \%$ of that of intravenous administration. Regarding fentanyl, the efficacy of intranasal fentanyl spray has been reported in several studies; these studies showed a rapid time to analgesic effect and indicated that the bioavailability of intranasal fentanyl was $89 \%$ of the intravenous bioavailability $[15,16]$. A more recent study indicated that pain could be significantly alleviated in 5 min in cancer patients with the intranasal administration of fentanyl; it is as effective as intravenous morphine in adults, and its bioavailability is $70 \%$ [17]. The intranasal bioavailability of ketamine can reach $50 \%$ and $45 \%$ of the intravenous bioavailability in children and adults, respectively [18]. To date, there have been few reports about the combined usage of ketamine, dexmedetomidine and fentanyl in AFOBI, either intravenously or intranasally.

The aim of this study was to evaluate the sedative and analgesic validity and the different administration routes of dexmedetomidine and fentanyl combined with ketamine in awake fiberoptic intubation.

\section{Methods}

\section{Ethical considerations}


The trial protocol was approved by the Clinical Research Ethics Committee of Shanghai Ninth People's Hospital affiliated with Shanghai Jiaotong University, School of Medicine (approval number, SH9H-2018T38-3). It was registered with the Chinese Clinical Trial Registry (www.chictr.org.cn; ChiCTR1900021185). Written informed consent was obtained from all participants or their legal representatives the day before surgery. This study adhered to CONSORT guidelines.

\section{Participants and groups}

We screened the patients the day before surgery and recruited those who met all the following criteria: (1) undergoing elective head and neck surgery with a predictive difficult airway and with BMI $>26 \mathrm{~kg} / \mathrm{m}^{2}$, toothless, obstructive sleep apnea hypopnea syndrome (OSAHS)/snoring, Mallampati grade III/IV, limited mandibular protrusion, short hyperthyroidism $(<6 \mathrm{~cm})$ and mass that may influence intubation; (2) age $\geq$ 16 and $<60$ years old; and (3) ASA physical status I or II. Patients who met any of the following criteria were excluded: (1) had chronic systemic diseases, such as high blood pressure, coronary disease, asthma, or thyroid disease (hyperthyroidism); (2) had cardiac electrophysiological disease, such as sinus bradycardia and atrioventricular heart blockage; (3) had intracranial hypertension or mental illness; and (4) special situations that needed to be determined by the chief surgeon.

A total of 36 patients in Shanghai Ninth People's Hospital were randomly assigned to 6 different groups $(n=6)$ : groups 1-3 received intravenous medication, while groups 4-6 received intranasal medication (group 1 DEX $1 \mu \mathrm{g} / \mathrm{kg}+\mathrm{FEN} 1 \mu \mathrm{g} / \mathrm{kg}$; groups 2-3: DEX $1 \mu \mathrm{g} / \mathrm{kg}+\mathrm{FEN} 0.7 \mu \mathrm{g} / \mathrm{kg}+\mathrm{KTM} 0.1 / 0.2 \mathrm{mg} / \mathrm{kg}$; group 4: DEX $1.5 \mu \mathrm{g} / \mathrm{kg}+$ FEN $1.4 \mu \mathrm{g} / \mathrm{kg}$; groups 5-6: DEX $1 \mu \mathrm{g} / \mathrm{kg}+\mathrm{FEN} 1 \mu \mathrm{g} / \mathrm{kg}+\mathrm{KTM} 0.4 / 0.6 \mathrm{mg} / \mathrm{kg}$ ). Random numbers were generated by professionals in the department of statistics and placed in random envelopes that were opened on the day of operation. Anesthesiologists administered drugs according to the patient's assigned subgroup. Patients and the personnel who collected and analyzed the data were blinded to the specific grouping.

\section{Anesthesia procedure and data collection}

Standard fasting guidelines were followed. No preoperative medication was administered. Patients lay in the supine position, and a peripheral vein in the dorsal venous hand or a cephalic vein was established. At the same time, the patient inhaled oxygen ( $2 \mathrm{~L} / \mathrm{min})$, and the electrocardiogram (ECG), noninvasive blood pressure (NIBP), pulse oxygen saturation $\left(\mathrm{SpO}_{2}\right)$, respiration rate (RR), and bispectral index (BIS) were recorded.

For the intravenous (IV) route (Fig. 1A), each group was given DEX (Guorui Medical, Inc., Sichuan, China; $0.1 \mathrm{mg} / \mathrm{ml}$ ) at a total dose of $1 \mu \mathrm{g} / \mathrm{kg}$ of body weight, which was diluted with sterile saline solution (Chimin Pharmaceutical Co., Ltd., Zhejiang, China) to a final concentration of $4 \mu \mathrm{g} / \mathrm{ml}$ and intravenously pumped for $10 \mathrm{~min}$. FEN (Humanwell Pharmaceutical Co., Ltd., Yichang, China; $0.05 \mathrm{mg} / \mathrm{ml}$ ) was given intravenously $6 \mathrm{~min}$ after dexmedetomidine administration. The dose given to group $1 \mathrm{was} 1 \mu \mathrm{g} / \mathrm{kg}$, and that given to groups 2 and 3 was $0.7 \mu \mathrm{g} / \mathrm{kg}$. Nine minutes later, groups 2 and 3 were intravenously injected with KTM (Gutian Medical, Inc., Fujian, China; $50 \mathrm{mg} / \mathrm{ml}$ ) at doses of $0.1 \mathrm{mg} / \mathrm{kg}$ or $0.2 \mathrm{mg} / \mathrm{kg}$ of 
body weight, respectively. After 10 min, the patients underwent thyrocricocentesis with $2 \%$ lidocaine hydrochloride (Hualu Pharmaceutical Co., Ltd., Shandong, China; $0.02 \mathrm{~g} / \mathrm{ml}$ ) for local anesthesia. Lidocaine aerosol (Xiangxue Pharmaceutical Co., Ltd., Guangzhou, China; $50 \mathrm{~g}: 1.2 \mathrm{~g}$ ) was sprayed into nose in preparation for intubation, and then the nasal cavity was contracted with ephedrine hydrochloride and nitrofurazone nasal drops (Winguide Huangpu, Shanghai, China; $10 \mathrm{ml}: 2 \mathrm{mg}$ ). Then, the patients were intubated intranasally with a fiberoptic bronchoscope. At the same time, the motor activity assessment scale (MAAS) score was determined (Table 1) [19]. All patients breathed spontaneously during the procedure.

For the intranasal (IN) groups (Fig. 1B), monitoring was the same as for the intravenous groups, and anesthetics were administered intranasally using a mucosal atomizer device (MAD, Wolfe Troy Medical Inc., Utah, USA). An independent investigator prepared and administered the anesthetics or placebo (0.9\% saline) with a $2.5-\mathrm{ml}$ syringe that was attached to an MAD via a lure lock connector. All the anesthetics used were diluted with $0.9 \%$ saline to a final volume of $1.5 \mathrm{ml}$. The unilateral nasal cavity administration volume was no more than $0.3 \mathrm{ml}$ each time, and administration intervals of 1 min were observed to ensure that the drug was completely absorbed through the nasal mucosa. Dexmedetomidine was given to group 4 or groups $5-6$ at a dose of $1.5 \mu \mathrm{g} / \mathrm{kg}$ or $1 \mu \mathrm{g} / \mathrm{kg}$ of body weight, respectively. Ten minutes later, ketamine at $0.4 \mathrm{mg} / \mathrm{kg}$ or $0.6 \mathrm{mg} / \mathrm{kg}$ was given to group 5 or group 6 , respectively. Then, $20 \mathrm{~min}$ later, fentanyl at $1.4 \mu \mathrm{g} / \mathrm{kg}$ or $1 \mu \mathrm{g} / \mathrm{kg}$ was given to group 4 or groups $5-6$, respectively. Thirty minutes later, local anesthesia was administered as described above, and nasal tracheal intubation was performed using fiberoptic bronchoscopy.

Vital signs such as $\mathrm{RR}, \mathrm{HR}, \mathrm{NIBP}$, and $\mathrm{SpO}_{2}$ were recorded before drug administration as the baseline and were collected every 5 min during the procedure. The modified observer's assessment of alertness/sedation Scale (OAA/S) score was assessed every 3 min three times and each minute after 9 min (1 Completely awake, responding normally to normal call responses; 2 Slow response to normal call; 3 No response to normal call, response to repeated loud calls; 4 No response to repeated loud calls, only response to tapping the body; 5 No response to slap the body, but response to noxious stimuli. No response to noxious stimuli is anesthesia). The MAAS score and the time required for the BIS to reach 6080 were recorded. Atropine $(0.5 \mathrm{mg})$ was given when HR was lower than 45 beats per minute, and $6 \mathrm{mg}$ ephedrine was given when systolic blood pressure (SBP) was lower than $90 \mathrm{mmHg}$ or diastolic blood pressure (DBP) was lower than $60 \mathrm{mmHg}$ or either dropped below $70 \%$ of the baseline value. The visual analog scale (VAS) score during intubation was noted. The VAS is a $10-\mathrm{cm}$ line with 0 at the left end indicating painless and 10 at the right indicating severe and unbearable pain. Patients could mark on the scale to match their pain level subjectively. In consideration of the lack of cooperation when sedated, patients were required to recall the level of pain during intubation and to mark on VAS on the first postoperative day. Anesthetics which might induce anterograde amnesia, such as midazolam, were not used in this study. All intubations were performed by the same senior anesthesiologist.

The primary endpoint was the VAS score. Secondary endpoints included the time required for the modified OAA/S score to reach above 2 and for the BIS value to decrease to 60-80; the MAAS score; 
changes in $\mathrm{HR}, \mathrm{RR}, \mathrm{NIBP}$, and $\mathrm{SpO}_{2}$; and the incidence of adverse reactions such as nausea, vomiting, coughing, sinus bradycardia and low blood pressure (a decrease in SBP/DBP of more than $30 \%$ compared to the baseline value).

\section{Statistical analysis}

Continuous variables were analyzed with one-way ANOVA or paired $t$-test. Categorical variables were analyzed with Chi-square test or Fisher's exact test. A $P$-value $<0.05$ was considered statistically significant. SPSS 24.0 for Windows (SPSS, Inc., Chicago, IL, USA) was used for all statistical analyses.

\section{Results}

\section{Participant characteristics}

A total of 36 patients were consecutively enrolled and randomized to 6 groups from February 1, 2019 to March 25, 2019. All participants were able to complete the study (Fig. 2), while being woken up during the intubation procedures. There was no significant difference in age, sex, or BMI among all patients (Table 2).

\section{Outcome analysis}

Primary outcome

All patients accomplished the VAS score after the operation. For IV groups, the VAS score of group 1 (5.65 $\pm 2.11)$ was higher than those of group $2(1.89 \pm 2.16, \mathrm{t}=3.043, \mathrm{df}=10, P=0.012,95 \% \mathrm{Cl} 1.01$ to 6.50$)$ and group $3(1.15 \pm 0.98, \mathrm{t}=4.733, \mathrm{df}=10, P=0.001,95 \% \mathrm{Cl} 2.38$ to 6.61$)$. The difference between group 2 and group 3 was not significant (Fig. 3A). For IN groups, the VAS score was lower in group 6 ( $0.86 \pm$ 1.27) than in group $4(7.20 \pm 2.70, \mathrm{t}=5.198, \mathrm{df}=10, P<0.001,95 \% \mathrm{Cl} 3.62$ to 9.05$)$ and group 5 (3.93 \pm $2.73, \mathrm{t}=2.499, \mathrm{df}=10, P=0.031,95 \% \mathrm{Cl} 0.33$ to 5.81 ) (Fig. 3B). Group 6 had the lowest score of all groups, which was significantly different from those of groups 1,4 and 5 .

\section{Secondary outcomes}

The time required for the OAA/S score to reach above 2 was not significantly different among IV groups or IN groups (Fig. 3C, D). There was no obvious difference in the time needed for the BIS to decrease to 60-80 (Fig. 3E, F) or in the MAAS score (Fig. 3G, H). The same results were obtained for HR, NIBP, and $\mathrm{SpO}_{2}$ (Fig. 4). In addition, we found that the respiration rates of group 1 and group 2 differed at the 10-, $15-$, and 20 -min time points, with a $P$ value $<0.05$. However, it was difficult to determine the difference among two drug administration due to initial differences among two groups at $0 \mathrm{~min}$.

We found that the participants in group 5 and group 6 were less likely to cough when intubated than those in group $4(16.67 \%, 16.67 \%, 100.00 \%$, respectively, $P=0.002)$, while no difference was found 
among IV groups. No significant differences in the incidences of other adverse effects (nausea, vomiting, sinus bradycardia and hypotension) were recorded among all groups.

\section{Discussion}

Our study found that the VAS score was inversely proportional to the dose of ketamine. Low doses of ketamine can result in satisfactory analgesic and sedation effects, which is essential for AFOBI procedures. Furthermore, the MAAS score of all groups were below 4 which confirmed the adequate analgesia and sedation effects by ketamine for AFOBI procedures.

The main purpose of medication during AFOBI is to keep patients responsive and cooperative while preventing potential respiratory and cardiovascular function depression [6, 21]. To achieve this, the anesthetic agents used during the procedure must have a fast onset of action, be easily titratable while providing adequate sedation [22]. The three anesthetics used in our study all acted quickly when administered intravenously with strong sedation and analgesia effects. Dexmedetomidine is often used at $1 \mu \mathrm{g} / \mathrm{kg}$ over $10 \mathrm{~min}$ as a loading dose with or without a maintenance dose of $0.3 \mu \mathrm{g} / \mathrm{kg} / \mathrm{h}$ to 0.7 $\mu \mathrm{g} / \mathrm{kg} / \mathrm{h}[9,23-28]$ in clinical scenarios. For the purpose of the present study, a loading dose of $1 \mu \mathrm{g} / \mathrm{kg}$ of DEX was infused intravenously over 10 min with no continuous infusion, considering that dexmedetomidine was given in combination with other anesthetics. Fentanyl takes $1 \mathrm{~min}$ to take effect when injected intravenously and 4 min to reach its peak, and the analgesia effect is maintained for 30 to $60 \mathrm{~min}$. The induction dosage of fentanyl for general anesthesia differs among various surgical procedures, ranging from $1 \mu \mathrm{g} / \mathrm{kg}$ to $4 \mu \mathrm{g} / \mathrm{kg}$. The final intravenous injection dosage of fentanyl was set at $1 \mu \mathrm{g} / \mathrm{kg}$ which was based on current literature [2]. A previous study reported that low doses of ketamine could provide analgesia and modulate opioid tolerance, which is consistent with our study [9]. Ketamine is typically administered intravenously and has a relatively short half-life (2-3 h). However, it is inconvenient for use in emergency settings [29]. There have been few studies on the use of ketamine in awake intubation. Considering that dexmedetomidine and fentanyl were administrated in junction, a final dosage gradient of $0.1 \mathrm{mg} / \mathrm{kg}$ and $0.2 \mathrm{mg} / \mathrm{kg}$ was set for IV, which is lower than the dosage used to treat cancer pain intravenously [30].

In our study, the incidences of coughing were lower in group 5 and group 6 than in group $4(P=0.002)$, indicating that ketamine could suppress coughing. A previous study reported that a mixture of ketamine and dexmedetomidine could suppress coughing induced by fentanyl which was consistent with our study [31]. However, no difference was found among the IV groups. The results of our study suggest that the addition of ketamine could reduce coughing, especially when administered intranasally. This outcome may result from the local anesthetic effect of ketamine [32].

In this study, we calculated the dosages of intranasally administered drugs according to their bioavailability. Considering that the dosage of ketamine was $0.75 \mathrm{mg} / \mathrm{kg}$ in the study of Andolfatto G. et al. [33], we chose lower doses of 0.4 and $0.6 \mathrm{mg} / \mathrm{kg}$. To achieve the maximum analgesic effect of drugs at the same time, we set the dosing interval by referring to the pharmacokinetic data reported in other 
studies. Intubation was performed when the blood concentrations of the three anesthetics were at their highest - that is, when sedation and analgesia were at their best - to minimize patients' pain and anxiety. However, it is worth noting that the long induction time of IN sedation may limit its application for emergency intubation procedures.

There were also a few limitations in our study. The sample size was not large enough due to the nature of the present study being an exploratory study. More samples should be recruited in the future. In addition, small doses of dexmedetomidine was given repeatedly due to inadequate pharmaceutical concentration of it.

We also noted a few tips that might ensure the effectiveness of intranasal administration. First, we examined the patients' nasal structure and mucosa, cleaned the nasal cavities and minimized the barriers to drug absorption. Second, we tried to increase the concentration of the drugs by not diluting them. Third, we used a special nasal spray device to distribute the drug evenly onto the nasal mucosa to reduce drug loss. Fourth, we performed nasal administration in both nasal cavities to increase the nasal mucosal surface area that could absorb the drugs. Fifth, an administration method that repeatedly provided a small amount of the drug was used, and the amount delivered to a single nasal cavity was controlled to be no more than $0.3 \mathrm{ml}$ at a time. Finally, the participants were asked to lean their heads back during spraying and to breathe with their mouths temporarily.

\section{Conclusions}

Our study indicated that the addition of subanesthetic doses of ketamine could reduce the dosages of fentanyl and dexmedetomidine required for AFOBI procedures while providing better sedative and analgesic effects both intravenously and intranasally. Furthermore, the addition of intranasal ketamine could suppress coughing during AFOBI procedure, while no difference was found for the groups that received intravenous ketamine.

\section{Declarations}

\section{Acknowledgments}

We thank all participants and their families for their cooperation with this study. We also thank our nurse anesthetists and staff members for their support and dedications.

\section{Authors' contributions}

$\mathrm{JH}, \mathrm{YJ}, \mathrm{LC}$, and PJ designed the project. LC wrote the manuscript with PJ and YJ providing revisions of the manuscript. LC and PJ recruited the subjects and clinical assessments and acquired the data. SY, HR and WH helped to design the overall study and analyze the data. All authors reviewed the final manuscript. All authors have given their final approval for the manuscript. 


\section{Funding}

This work was supported by National Natural Science Foundation of China $(81870818,81901070)$ and Shanghai Pujiang Program (2019PJD025), Shanghai Sailing Program (19YF1427700), Seed Founding of Shanghai Ninth People's Hospital, Shanghai Jiao Tong University School of Medicine (JYZZ047), Funding of Shanghai Jiao Tong University School of Medicine (TM201715), Natural Science Foundation of Shanghai (17DZ1205403). The funding agents play no role in the study design, data collection, analysis, interpretation of data or in writing the manuscript.

\section{Availability of data and materials}

The datasets supporting the conclusions of this article are included within the article.

\section{Ethics approval and consent to participate}

The trial protocol was approved by the Clinical Research Ethics Committee of Shanghai Ninth People's Hospital affiliated with Shanghai Jiaotong University, School of Medicine (approval number, SH9H-2018T38-3). Written informed consent was obtained from all participants or their legal representatives the day before surgery.

\section{Consent for publication}

Participants have expressed their consent for anonymized data publication in written or verbal form.

\section{Competing interests}

The authors declare that they have no competing interests.

\section{Abbreviations}

AFOBI: awake fiberoptic bronchoscope intubation; DEX: dexmedetomidine; FEN: fentanyl; KTM: ketamine; IV: intravenous; IN: intranasal; VAS: visual analog scale; OAA/S: observer's assessment of alertness/sedation scale; BIS: bispectral index; MAAS: motor activity assessment scale; ECG: electrocardiogram; HR, heart rate; SBP, systolic blood pressure; DBP, diastolic blood pressure; NIBP, noninvasive blood pressure; $\mathrm{SpO}_{2}$, pulse oxygen saturation; $\mathrm{RR}$, respiration rate.

\section{References}

[1] Shiga T, Wajima Z, Inoue T, Sakamoto A. Predicting difficult intubation in apparently normal patients: a meta-analysis of bedside screening test performance. Anesthesiology. 2005;103(2):429-37.

[2] Liu H, Zhou T, Wei J. Comparison between remifentanil and dexmedetomidine for sedation during modified awake fiberoptic intubation. Exp Ther Med. 2015;9(4):1259-64. 
[3] Rosenstock CV, Thogersen B, Afshari A, Christensen AL, Eriksen C, Gatke MR. Awake fiberoptic or awake video laryngoscopic tracheal intubation in patients with anticipated difficult airway management: a randomized clinical trial. Anesthesiology. 2012;116(6):1210-6.

[4] Mendonca C, Mesbah A, Velayudhan A, Danha R. A randomised clinical trial comparing the flexible fibrescope and the Pentax Airway Scope (AWS)(®)for awake oral tracheal intubation. Anaesthesia. 2016;71(8):908-14.

[5] Tsai CJ, Chu KS, Chen TI, Lu DV, Wang HM, Lu IC. A comparison of the effectiveness of dexmedetomidine versus propofol target-controlled infusion for sedation during fibreoptic nasotracheal intubation. Anaesthesia. 2010;65(3):254-9.

[6] He XY, Cao J, He Q, Shi XY. Dexmedetomidine for the management of fibreoptic intubation. Cochrane Db Syst Rev [Online serial]. 2014;1(1):CD009798.

[7] Li CW, Li YD, Tian HT, Kong XG, Chen K. Dexmedetomidine-midazolam versus sufentanil-midazolam for awake fiberoptic nasotracheal intubation: A randomized double-blind study, Chin. Med. J. (Engl). 2015;128(023):3143-8.

[8] Cabrini L, Baiardo RM, Ball L. Awake Fiberoptic Intubation Protocols in the Operating Room for Anticipated Difficult Airway: A Systematic Review and Meta-analysis of Randomized Controlled Trials. Anesth Analg. 2019;128(5):971-80.

[9] Schmid RL, Sandler AN, Katz J. Use and efficacy of low-dose ketamine in the management of acute postoperative pain: A review of current techniques and outcomes. Pain. 1999;82(2):111-25.

[10] Ferguson I, Alkhouri H, Fogg T, Aneman A. Ketamine use for rapid sequence intubation in Australian and New Zealand emergency departments from 2010 to 2015: A registry study. Emerg Med Australas. 2019;31(2):205-10.

[11] Mogahd MM, Mahran MS, Elbaradi GF. Safety and efficacy of ketamine-dexmedetomidine versus ketamine-propofol combinations for sedation in patients after coronary artery bypass graft surgery. Ann Card Anaesth. 2017;20(2):182-7.

[12] Chen J-Y, Jia J-E, Liu T-J, Qin M-J, Li W-X. Comparison of the effects of dexmedetomidine, ketamine, and placebo on emergence agitation after strabismus surgery in children. Can $\mathrm{J}$ Anesth Can d'anesthésie. 2013;60(4):385-92.

[13] Chun EH, Han MJ, Baik HJ, Park HS, Chung RK, Han Jl. Dexmedetomidine-ketamine versus Dexmedetomidine-midazolam-fentanyl for monitored anesthesia care during chemoport insertion: A Prospective Randomized Study. BMC Anesthesiol. 2016;16(1):1-9.

[14] Li A, Yuen VM, Goulay-Dufaÿ S, Sheng Y, Standing JF, Kwok PCL. Pharmacokinetic and pharmacodynamic study of intranasal and intravenous dexmedetomidine. $\mathrm{Br} \mathrm{J}$ Anaesth. 
2018;120(5):960-8.

[15] Thronæs M, Popper L, Eeg M, Jaatun E, Kvitberg M, Kaasa S. Efficacy and Tolerability of Intranasal Fentanyl Spray in Cancer Patients with Breakthrough Pain. Clin Ther. 2015;37(3):585-96.

[16] Foster D, Upton R, Christrup L, Popper L. Pharmacokinetics and pharmacodynamics of intranasal versus intravenous fentanyl in patients with pain after oral surgery. Ann Pharmacother. 2008;42(10):1380-7.

[17] Chew KS, Shaharudin AH. An open-label randomised controlled trial on the efficacy of adding intranasal fentanyl to intravenous tramadol in patients with moderate to severe pain following acute musculoskeletal injuries. Singapore Med J. 2017;58(10):601-5.

[18] Yanagihara Y, Ohtani M, Kariya S, Uchino K, Hiraishi T, Ashizawa N. Plasma concentration profiles of ketamine and norketamine after administration of various ketamine preparations to healthy Japanese volunteers. Biopharm Drug Dispos. 2003;24(1):37-43.

[19] Bement MH, Weyer A, Keller M, Harkins AL, Hunter SK. Anxiety and stress can predict pain perception following a cognitive stress. Physiology and Behavior, 2010, 101(1):87-92.

[20] Devlin J. Motor activity assessment scale; a valid and reliable sedation scale for use with mechanically ventilated patients in an adult surgical intensive care unit. Crit Care Med. 1999;27(7):1271.

[21] Zhang Y, Shan GJ, Zhang YX, Cao SJ, Zhu SN, Li HJ. Propofol compared with sevoflurane general anaesthesia is associated with decreased delayed neurocognitive recovery in older adults. $\mathrm{Br} \mathrm{J}$ Anaesth. 2018;121(3):595-604.

[22] Cattano D, Lam NC, Ferrario L, Seitan C, Vahdat K, Wilcox DW. Dexmedetomidine versus remifentanil for sedation during awake fiberoptic intubation. Anesthesiol Res Pract. 2015;2012(9):753107.

[23] Shen SL, Xie Y hong, Wang WY, Hu SF, Zhang YL. Comparison of dexmedetomidine and sufentanil for conscious sedation in patients undergoing awake fibreoptic nasotracheal intubation: A prospective, randomised and controlled clinical trial. Clin Respir J. 2014;8(1):100-7.

[24] Hu R, Liu JX, Jiang H. Dexmedetomidine versus remifentanil sedation during awake fiberoptic nasotracheal intubation: A double-blinded randomized controlled trial. J Anesth. 2013;27(2):211-7.

[25] Soliman PT, Langley G, Munsell MF, Vaniya HA, Frumovitz M, Ramirez PT. Analgesic and antiemetic requirements after minimally invasive surgery for early cervical cancer: A comparison between laparoscopy and robotic surgery. Ann Surg Oncol. 2013;20(4):1355-9.

[26] El Mourad MB, Elghamry MR, Mansour RF, Afandy ME. Comparison of intravenous dexmedetomidinepropofol versus ketofol for sedation during awake fiberoptic intubation: A prospective, randomized study. Anesthesiol Pain Med. 2019;9(1):1-8. 
[27] Xu T, Li M, Ni C, Guo XY. Dexmedetomidine versus remifentanil for sedation during awake intubation using a Shikani optical stylet: A randomized, double-blinded, controlled trial. BMC Anesthesiol. 2015;16(1):52.

[28] Kumar P, Kaur T, Atwal GK, Bhupal JS, Basra AK. Comparison of intubating conditions using fentanyl plus propofol versus fentanyl plus midazolam during fiberoptic laryngoscopy. J Clin Diagnostic Res. 2017;11(7):UC21-UC24.

[29] Palareti G, Legnani C, Cosmi B, Antonucci E, Erba N, Poli D. Comparison between different D-Dimer cutoff values to assess the individual risk of recurrent venous thromboembolism: Analysis of results obtained in the DULCIS study. Int J Lab Hematol. 2016;38(1):42-9.

[30] Mercadante S, Prestia G, Adile C, Casuccio A. Intranasal fentanyl versus fentanyl pectin nasal spray for the management of breakthrough cancer pain in doses proportional to basal opioid regimen. $J$ Pain. 2014;15(6):602-7.

[31] Saleh AJ, Zhang L, Hadi SM, Ouyang W. A priming dose of intravenous ketamine-dexmedetomidine suppresses fentanyl-induced coughing: A double-blind, randomized, controlled study. Ups J Med Sci. 2014;119(4):333-7.

[32] Farnia MR, Jalali A, Vahidi E, Momeni M, Seyedhosseini J, Saeedi M. Comparison of intranasal ketamine versus IV morphine in reducing pain in patients with renal colic. Am J Emerg Med. 2017;35(3):434-7.

[33] Andolfatto G, Innes K, Dick W, Jenneson S, Willman E, Stenstrom R. Prehospital Analgesia With Intranasal Ketamine: A Randomized Double-Blind Trial in Adults. Ann Emerg Med. 2019;74(2):241-50.

\section{Tables}

Table 1 Motor Activity Assessment Scale (MAAS)[20]. 


\begin{tabular}{|c|c|c|}
\hline Score & Description & Definition \\
\hline 0 & Unresponsive & Does not move with noxious stimuli \\
\hline 1 & $\begin{array}{l}\text { Responsive } \\
\text { only to }\end{array}$ & $\begin{array}{c}\text { Open eyes, raises eyebrows or turns head toward stimulus; moves limbs with noxious } \\
\text { stimulus }\end{array}$ \\
\hline 2 & $\begin{array}{l}\text { noxious } \\
\text { stimuli }\end{array}$ & $\begin{array}{c}\text { Open eyes, raises eyebrows or turns head toward stimulus when touched or name is } \\
\text { loudly spoken }\end{array}$ \\
\hline 3 & $\begin{array}{l}\text { Responsive to } \\
\text { touch or }\end{array}$ & $\begin{array}{c}\text { No external stimulus in required to elicit movement; adjusts sheets or clothes } \\
\text { purposefully, follows commands }\end{array}$ \\
\hline 4 & $\begin{array}{c}\text { name } \\
\text { Calm and }\end{array}$ & $\begin{array}{c}\text { No external stimulus in required to elicit movement; picks at sheets or tubes, } \\
\text { uncovers self, follows commands }\end{array}$ \\
\hline 5 & cooperative & \multirow{3}{*}{$\begin{array}{c}\text { No external stimulus in required to elicit movement, attempts to sit up or moves limbs } \\
\text { out of bed, does not consistently follow commands (for example, will lie down when } \\
\text { asked to but soon reverts back to attempts to sit up or move limbs out of bed) } \\
\text { No external stimulus in required to elicit movement; pulls at tubes or catheters, } \\
\text { thrashes side to side, strikes at staff, tries to climb out of bed, does not calm down } \\
\text { when asked }\end{array}$} \\
\hline \multirow{3}{*}{6} & $\begin{array}{l}\text { Restless and } \\
\text { cooperative }\end{array}$ & \\
\hline & Agitated & \\
\hline & $\begin{array}{l}\text { Dangerously } \\
\text { agitated, } \\
\text { uncooperative }\end{array}$ & \\
\hline
\end{tabular}

Table 2 Baseline characteristics.

\begin{tabular}{ccccccc}
\hline target & 1 & 2 & 3 & 4 & 5 & 6 \\
\hline Age (yr) & $44.83 \pm$ & $41.33 \pm$ & $35.17 \pm$ & $37.50 \pm$ & $25.33 \pm$ & $39.67 \pm$ \\
Sex (Male) & 15.88 & 13.98 & 14.76 & 16.23 & 5.47 & 12.03 \\
Sex & $50 \%$ & $83.33 \%$ & $50 \%$ & $33.33 \%$ & $66.67 \%$ & $33.33 \%$ \\
(Female) & $50 \%$ & $16.67 \%$ & $50 \%$ & $66.67 \%$ & $33.33 \%$ & $66.67 \%$ \\
BMI & $22.03 \pm 2.55$ & $21.60 \pm 1.79$ & $22.23 \pm 3.16$ & $20.00 \pm 1.46$ & $21.17 \pm$ & $21.05 \pm 2.61$ \\
& & & & & 3.78 & \\
\hline
\end{tabular}

Data are presented as the mean (SD) \pm median (interquartile range) or percentage (\%) of patients.

\section{Figures}


A

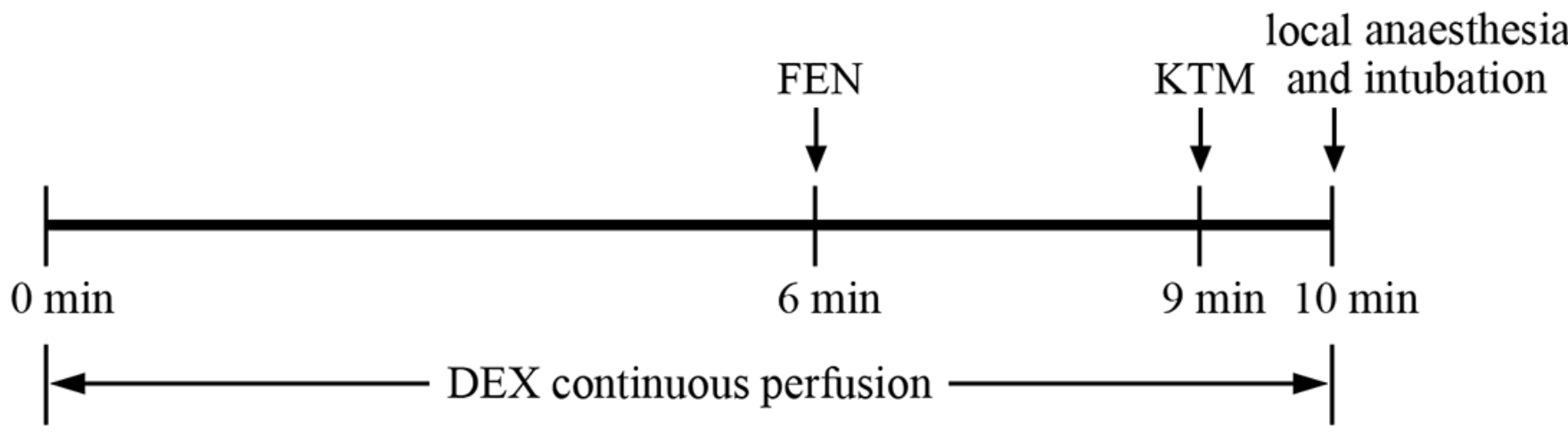

B

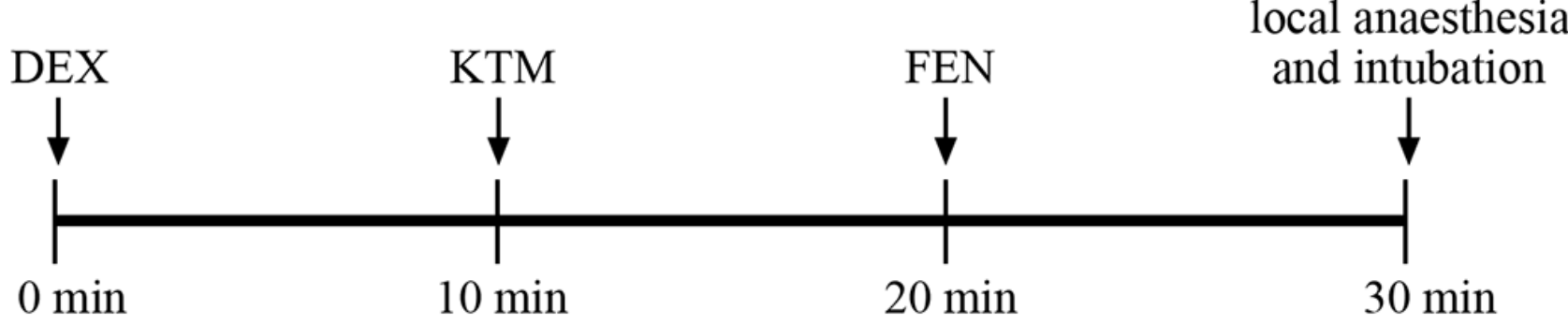

Figure 1

Drug administration flow. A. Intravenous (IV) administration. B. Intranasal (IN) administration. KTM, ketamine; DEX, dexmedetomidine; FEN, fentanyl. IV groups: group 1: DEX $1 \mu \mathrm{g} / \mathrm{kg}+\mathrm{FEN} 1 \mu \mathrm{g} / \mathrm{kg}$; groups 2-3: DEX $1 \mu \mathrm{g} / \mathrm{kg}+$ FEN $0.7 \mu \mathrm{g} / \mathrm{kg}+\mathrm{KTM} 0.1 / 0.2 \mathrm{mg} / \mathrm{kg}$; IN groups: group 4: DEX $1.5 \mu \mathrm{g} / \mathrm{kg}+$ FEN 1.4 $\mu \mathrm{g} / \mathrm{kg}$; and groups 5-6: DEX $1 \mu \mathrm{g} / \mathrm{kg}+\mathrm{FEN} 1 \mu \mathrm{g} / \mathrm{kg}+\mathrm{KTM} 0.4 / 0.6 \mathrm{mg} / \mathrm{kg}$. 


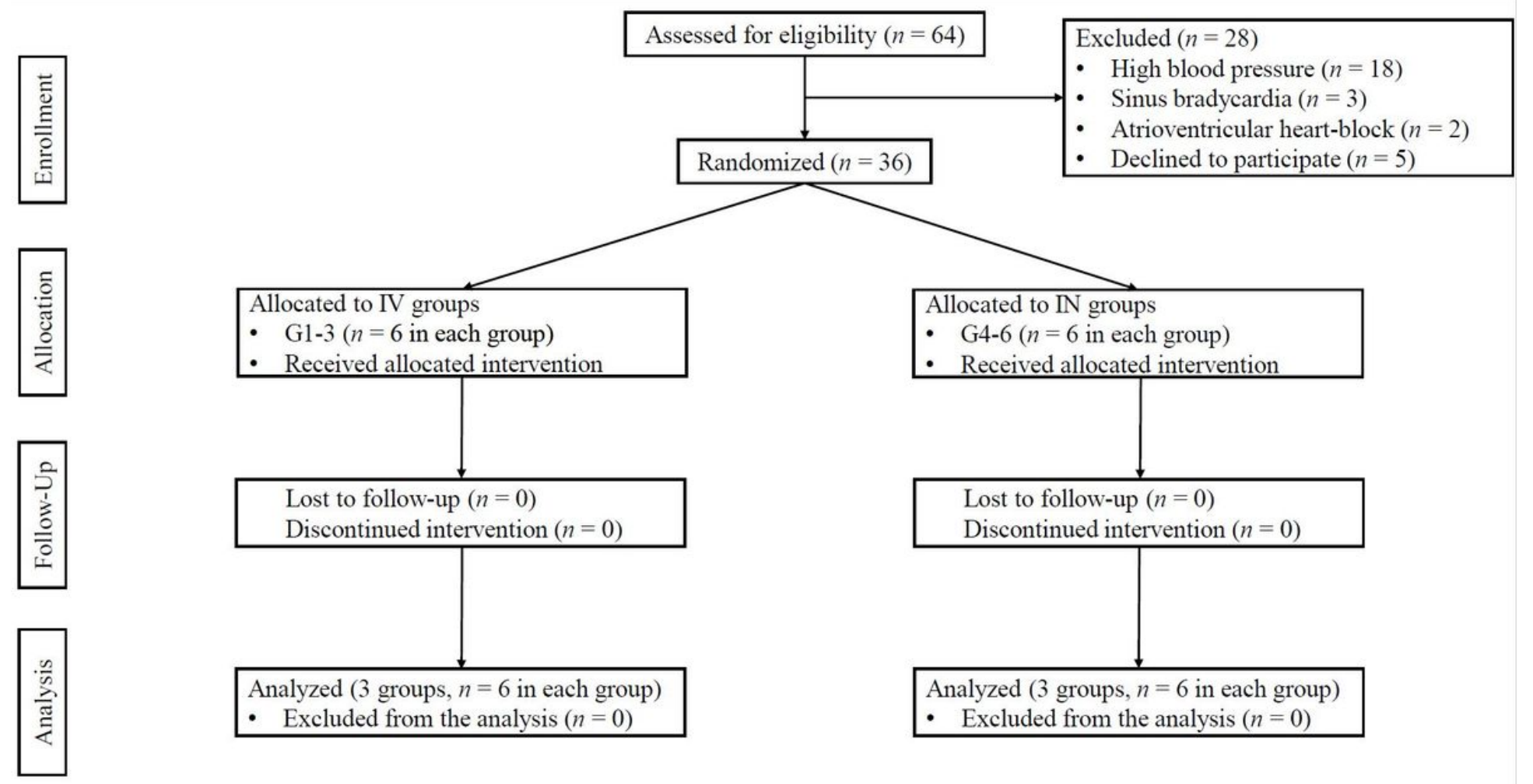

Figure 2

CONSORT diagram.
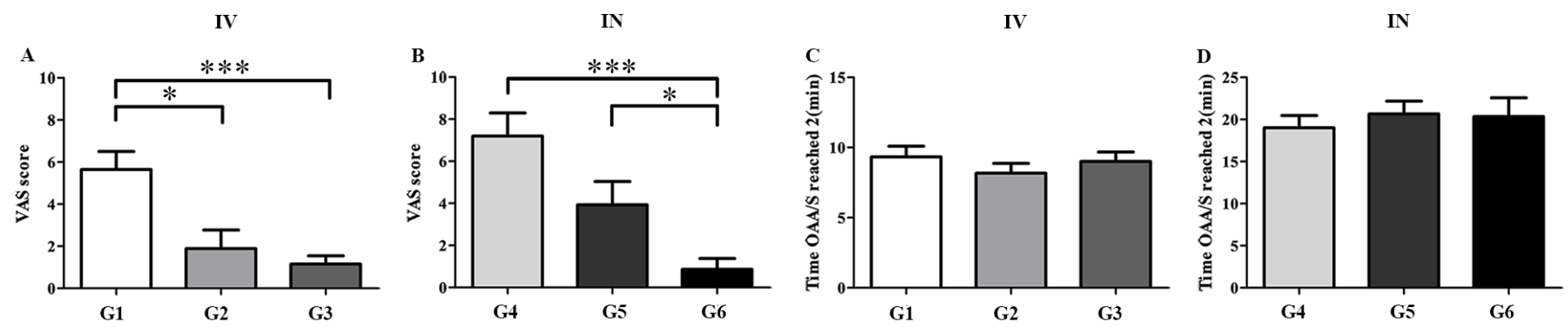

$\mathbf{E}$

$\mathbf{F}$

G

H
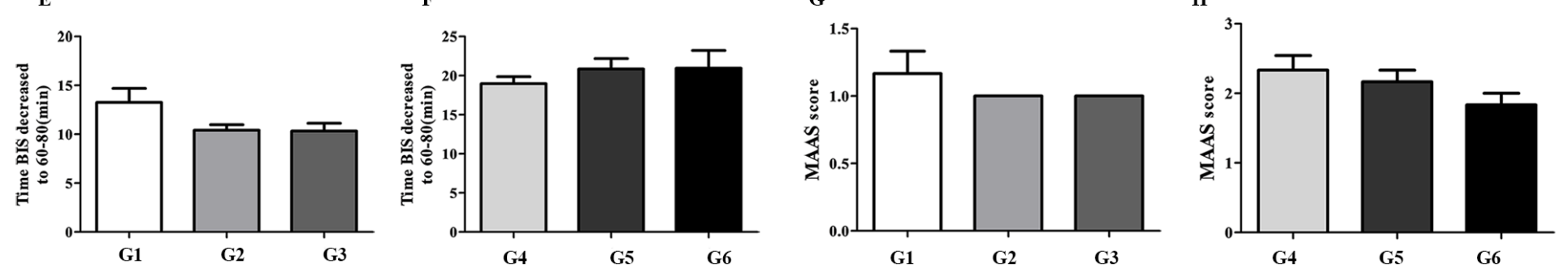

Figure 3

Degree of analgesia and sedation. A-B. VAS score. For intravenous administration, the ketamineconjugated group received reduced doses of dexmedetomidine and fentanyl, and the VAS score was lower in group 2 and group 3 than in group 1 ( $P$ values are 0.012 and 0.001 ). For intranasal 
administration, the VAS score of group 6 was significantly lower than that of group $4(P<0.001)$ and group $5(P=0.031)(G$, group; $*, P<0.05 ; * \star, P<0.01$; $* \star *, P<0.001)$. C-D. The times required for OAA/S to reach above 2. E-F. The times required for BIS to decrease to 60-80. G-H. MAAS scores. For C-H, there were no significant differences among the IV groups or the IN groups.
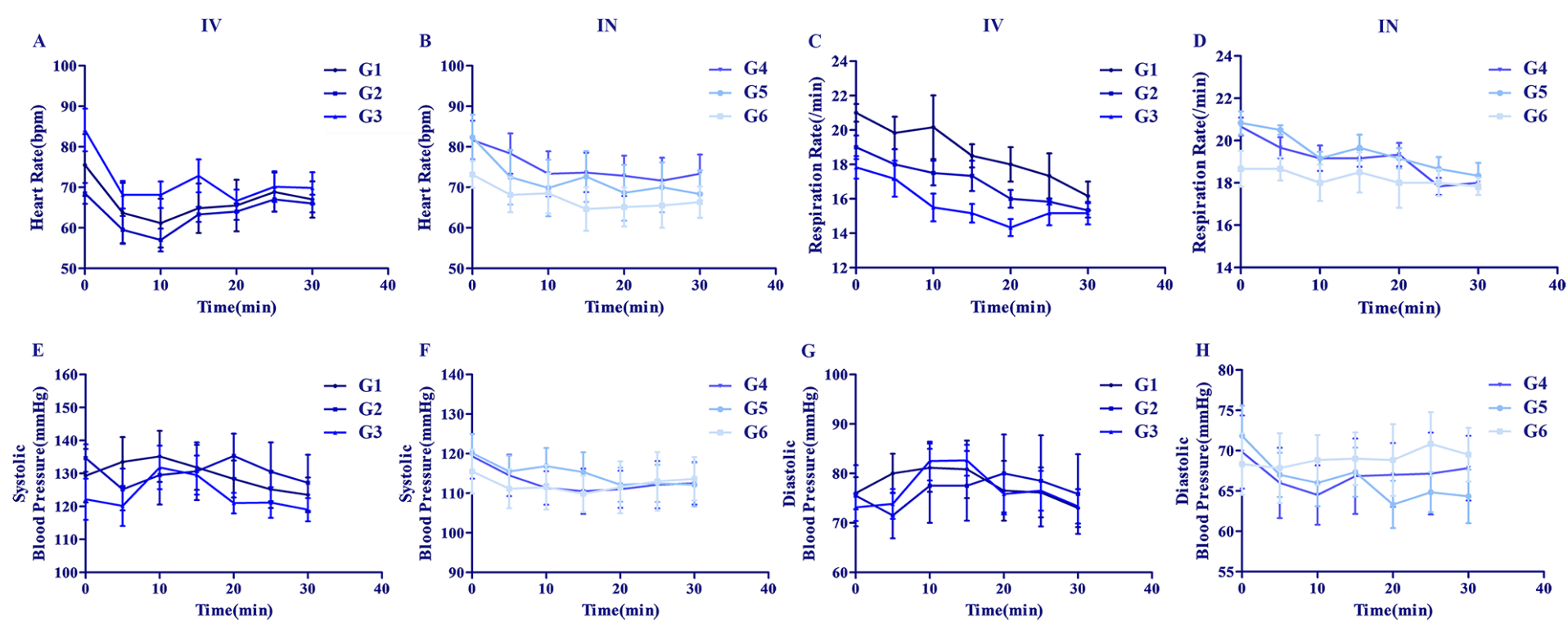

\section{Figure 4}

Changes in vital signs. There were no significant differences in vital signs among the IV groups or the IN groups. A-B. Heart rate; C-D. Respiration rate; E-F. Systolic blood pressure; G-H. Diastolic blood pressure.

\section{Supplementary Files}

This is a list of supplementary files associated with this preprint. Click to download.

- CONSORTChecklist.doc 